\title{
Frequency and Antimicrobial Susceptibility of the Bacteria Isolated from Blood Cultures of Neonatal
}

\author{
Ban Mahdi Shakir ${ }^{1} \quad$ Sinaa Mahdi Shakir ${ }^{2} \quad$ Nadheema Hammood Hussein $^{3} \quad$ Khetam Habeeb Rasool ${ }^{3}$ \\ 1.Imam Sadiq General Hospital, Babil Health Directorate, Ministry of Health , Iraq. \\ 2.Teaching Laboratories Medical City, Ministry of Health , Iraq. \\ 3.Department of Biology, College of Science, Mustansiryah University, Iraq.
}

\begin{abstract}
The present study was carried out to determine the prevalence of bacterial isolates responsible for blood stream infection (BSI) among neonatal inpatients at Baghdad Teaching Hospital / Baghdad and to also get an updated knowledge about their antibiotic resistance pattern during the period extended from 1 October till 31 December, 2018. All blood cultures were done by BacT/ALERT 3D device (Bio-Merieux, France). Identification of pathogenic bacteria at species level was done by using API system (Bio-Merieux, France) and the antimicrobial susceptibility testing was done by Kirby-Bauer method. A total of 90 blood cultures were received from neonatal suspected with blood stream infections. Out of 36 positive blood cultures, the incidence of positive blood cultures was higher among males $22(61.1 \%)$ than of females $14(38.9 \%)$. Out of 36 positive blood cultures, the isolation rate of Gram positive and Gram negative isolates was $25(69.4 \%)$ and 11(30.6\%), respectively. Coagulase negative Staphylococci (CoNS) was the most frequently isolated bacteria in blood cultures, 17 $(47.22 \%)$ isolates. Our study also showed that Klebsiella pneumoniae was the most frequently isolated Gram negative bacteria in blood specimens from neonatal inpatients $6(16.67 \%)$. The most effective antibiotic on Gram-positive isolates was Vancomycin, while for Gram negative bacteria the most effective antibiotic was Imipenem.
\end{abstract}

Keywords: Blood stream infection, Antimicrobial susceptibility, Neonatal blood cultures and Bacterial isolates DOI: $10.7176 / \mathrm{JBAH} / 9-14-05$

Publication date:July $31^{\text {st }} 2019$

\section{Introduction}

Blood stream infection (BSI) is a serious problem that needs immediate attention and treatment. It is a cause of high mortality especially if caused by multidrug resistant bacteria (Murty, and Gyaneshwari, 2007; Hussein, et al. 2015). They are potentially life-threatening and require rapid identification and also antibiotic susceptibility testing of the causative agent in order to facilitate specific antimicrobial therapy (Berit, et al. 2006). Bacteriological culture to isolate the offending pathogen and knowledge about sensitivity pattern of the isolates remain the main stay of definitive diagnosis and managementof bloodstream infections (Shahla, et al. 2009; Hussein, et al.2015). The results of bacteriological cultures and antibiotic susceptibility tests take 3-4 days. One key determinant in the ultimate outcome of patients with sepsis is institution of early and appropriate antimicrobial therapy. Thus it is a common practice to institute early empirical therapy with broad-spectrum antibiotics in patients presenting with clinical features suggestive of bacteraemia (Shahla, et al. 2009). Untreated and clinically significant bacteremia progresses to systemic inflammatory response syndrome (SIRS), sepsis, septic shock, and multiple organ dysfunction syndrome (MODS) (Butler-Laporte, et al. 2018). Blood culture is one of the most important bacteriological examinations with important clinical and therapeutic consequences. Blood cultures should be ordered in all patients with signs suggesting septicemia, endocarditis or severe infection (Gaynes, and Edwards,.2005). Bacteremia requires urgent and appropriate antibiotics. Delay in the administration of appropriate antibiotics is associated with increased morbidity and mortality (Arientová, et al. 2018; Banik, et al. 2018). In developing countries, more than 14 million deaths of children under five years of age occur during the childhood(Kalantar, et al. 2008), with infections accounting for up to $70 \%$ of total mortality for this age group (Mylotte, and Tayara, 2001). The aim of this study was to determine the frequency of bacteria that isolates from blood cultures of neonatal and their antimicrobial susceptibility in one hospital in Baghdad.

\section{Methods:}

2.1 Clinical specimens

A total of 90 blood specimens were collected (collected with duplicate) from 90 neonatal patients suspected with blood stream infections.

\subsection{Location of study}

This study was carried out at Baghdad Teaching Hospital and all blood specimens were collected from neonatal patients in the neonatal unit in this hospital. 


\subsection{Period of Study}

This study was done during the period extended from 1 October till 31 December, 2018.

\subsection{Collection of blood specimens}

All blood samples were collected from neonatal inpatients suspected with blood stream infections prior to initiation of antimicrobial therapy. Blood samples were collected with duplicate blood specimens. For each blood culture, $1-2 \mathrm{~mL}$ of blood were obtained from neonatal ( $\geq 0.5 \mathrm{~mL}$ for infants $<1$ month of age and $\geq 1 \mathrm{~mL}$ for children between 1 month to 30 months of age) (Connell, et al. 2007).

\subsection{Isolation and Identification of bacterial isolates}

Blood specimens were cultured by used BacT/ALERT 3D device (Bio-Merieux, France), and the bacteria were isolated from all specimens according to standard microbiology methods (Murray, et al.2003), then microorganisms were identified at species level by using API system (Bio-Merieux, France).

\subsection{Antimicrobial Susceptibility Test}

Kirby-Bauer method was followed as described by WHO, (WHO, (World Health Organization). 2003) to carry out the antibiotics susceptibility test for different antibiotics used in this study including: Oxacillin, Erythromycin, Levofloxacin, Vancomycin, Aoxicillin/Clavulanic acid, Piperacillin/Tazobbactam, Ceftriaxon, Ceftazidime, Gentamicin, Imipenem, Amikacin, Piperacillin, Tobramycin, Cefotaxime, Amikacin, Chloramphenicol and Trimethoprime- Sulphamethoxazole.

Inhibition zones developed around the discs were measured by millimeter $(\mathrm{mm})$ using a metric ruler according to Clinical Laboratories Standards Institute (CLSI, (Clinical and Laboratory Standards Institute) 2011). The isolate was interpreted as susceptible or resistant to a particular drug by comparison with standards inhibition zones.

\section{Results}

\subsection{Study patients}

Blood specimens were collected from 90 neonatal inpatients suspected with blood stream infections at Baghdad teaching hospital, along three months of study (from 1 October till 31 December, 2018). The age of neonatal patients ranged from 3 days to one month. The incidence of patients was higher among males $70(77.78 \%)$ than that of females $20(22.22 \%)$.

\subsection{Blood culture}

The frequency of positive blood culture that indicates true bacteremia in the studied patients was $36(40 \%)$ cases out of 90 blood specimens. The incidence of majority positive blood cultures was higher among males $22(61.1 \%)$ than that of females $14(38.9 \%)$.

\subsection{Frequency of bacteria isolated from blood culture}

In this study, the frequency of isolated bacteria that causing true bacteremia among neonatal inpatients was summarized in Table- 1 and Table-2, in these tables out of 36 positive blood cultures, the isolation rate of Gram positive and Gram negative bacteria was $25(69.4 \%)$ and 11(30.6\%), respectively.

From the 22 positive blood cultures among the males, $16(72.7 \%)$ isolates were Gram positive isolates and 6 $(27.3 \%)$ were Gram negative isolates. On the other hand $9(64.3 \%)$ isolates were Gram positive isolates and 5 $(35.7 \%)$ were Gram negative out of 14 positive blood cultures among the females.

Table-1: Frequency of bacteria isolates isolated from blood cultures of males

\begin{tabular}{|l|c|c|}
\hline Gram positive bacteria & NO. & \% \\
\hline Coagulase negative staphylococci & $\mathbf{1 0}$ & $\mathbf{4 5 . 4 5}$ \\
\hline Staphylococcus aureus & $\mathbf{2}$ & $\mathbf{9 . 0 9}$ \\
\hline Streptococcus spp. & $\mathbf{4}$ & $\mathbf{1 8 . 1 8}$ \\
\hline Gram negative bacteria & & \\
\hline Klebsiella pneumoniae & $\mathbf{3}$ & $\mathbf{1 3 . 6 4}$ \\
\hline Acinetobacter baumannii & $\mathbf{2}$ & $\mathbf{9 . 0 9}$ \\
\hline Serratia marcescens & $\mathbf{1}$ & $\mathbf{4 . 5 5}$ \\
\hline Total & $\mathbf{2 2}$ & $\mathbf{1 0 0}$ \\
\hline
\end{tabular}


Table-2: Frequency of bacteria isolates isolated from blood cultures of females

\begin{tabular}{|l|c|c|}
\hline Gram positive bacteria & NO. & $\%$ \\
\hline Coagulase negative staphylococci & $\mathbf{7}$ & $\mathbf{5 0}$ \\
\hline Staphylococcus aureus & $\mathbf{1}$ & $\mathbf{7 . 1 4}$ \\
\hline Streptococcus spp. & $\mathbf{1}$ & $\mathbf{7 . 1 4}$ \\
\hline Gram negative bacteria & & \\
\hline Klebsiella pneumoniae & $\mathbf{3}$ & $\mathbf{2 1 . 4 4}$ \\
\hline Acinetobacter baumannii & $\mathbf{1}$ & $\mathbf{7 . 1 4}$ \\
\hline Enterobacter cloacae & $\mathbf{1}$ & $\mathbf{7 . 1 4}$ \\
\hline Total & $\mathbf{1 4}$ & $\mathbf{1 0 0}$ \\
\hline
\end{tabular}

As shown in Table -1 and Table -2, coagulase negative staphylococci (CoNS) were the most frequently isolated bacteria in the blood cultures under study, 17(47.22\%). It also shown in Table -1 and Table -2 , that Klebsiella pneumoniae isolates 6(16.67\%) were the most frequently isolated Gram negative bacteria in blood culture of neonatal patients.

\subsection{Antimicrobial susceptibility test}

The susceptibility rate of Gram positive and Gram negative bacteria to all antibiotics under study was summarized in Table -3 and Table- 4, respectively. In Gram positive bacteria the most effective antibiotic was Vancomycin which showed $96 \%$ sensitivity rate followed by Levofloxacin $80 \%$. This study also showed a highest resistance to Erythromycin. On the other hand, the Gram positive isolates were revealed different degrees of resistance towards remaining antibiotics under study as shown in Table -3 .

Table-3: Susceptibility rate of Gram-positive bacteria under study towards various antibiotics.

\begin{tabular}{|l|c|l|l|}
\hline \multirow{2}{*}{ Antibiotics } & $\begin{array}{c}\text { Coagulase negative } \\
\text { staphylococci } \\
\mathbf{N = 1 7}\end{array}$ & $\begin{array}{c}\text { Staphylococcus } \\
\text { aureus } \\
\mathbf{N}=\mathbf{3}\end{array}$ & $\begin{array}{c}\text { Streptococcus } \\
\text { spp. } \\
\mathbf{N}=\mathbf{5}\end{array}$ \\
\cline { 2 - 5 } & $\mathbf{S \%}$ & $\mathbf{1} \%$ & $\mathbf{S \%}$ \\
\hline Oxacillin & $\mathbf{8}$ & $\mathbf{0}$ & $\mathbf{2}$ \\
\hline Erythromycin & $\mathbf{4}$ & $\mathbf{0}$ & $\mathbf{1}$ \\
\hline Aoxicillin/Clavulanic acid & $\mathbf{8}$ & $\mathbf{2}$ & $\mathbf{2}$ \\
\hline Vancomycin & $\mathbf{1 7}$ & $\mathbf{1}$ & $\mathbf{5}$ \\
\hline Piperacillin/Tazobbactam & $\mathbf{1 1}$ & $\mathbf{2}$ & $\mathbf{3}$ \\
\hline Levofloxacin & $\mathbf{1 5}$ & $\mathbf{1}$ & $\mathbf{2}$ \\
\hline Gentamicin & $\mathbf{5}$ & $\mathbf{0}$ & $\mathbf{1}$ \\
\hline Piperacillin & $\mathbf{7}$ & $\mathbf{0}$ & $\mathbf{2}$ \\
\hline Tobramycin & $\mathbf{6}$ & $\mathbf{1}$ & $\mathbf{3}$ \\
\hline Chloramphenicol & $\mathbf{1 3}$ & $\mathbf{1}$ & $\mathbf{3}$ \\
\hline Trimethoprime- & $\mathbf{1 1}$ & & \\
Sulphamethoxazole & & & \\
\hline
\end{tabular}

In Gram-Negative bacteria isolates, the rate of sensitivity to Aoxicillin/Clavulanic acid was very low (18.18\%) followed by Tobramycin, while the most effective antibiotic against Gram-negative bacteria was imipenem which showed sensitivity rate $100 \%$ for all Gram-negative bacteria under study. On the other hand, the Gram-negative bacteria under study were revealed different degrees of sensitivity towards remaining antibiotics as shown in Table -4 . 
Table-4: Susceptibility of Gram-negative bacteria under study towards various antibiotics.

\begin{tabular}{|l|c|c|c|c|}
\multirow{2}{*}{$\begin{array}{c}\text { Antibiotics } \\
\text { Amipenem }\end{array}$} & $\begin{array}{c}\text { Klebsiella } \\
\text { pneumoniae } \\
\mathbf{N = 6}\end{array}$ & $\begin{array}{c}\text { Acinetobacter } \\
\text { baumannii } \\
\mathbf{N = 3}\end{array}$ & $\begin{array}{c}\text { Serratia } \\
\text { marcescens } \\
\mathbf{N = 1}\end{array}$ & $\begin{array}{c}\text { Enterobacter } \\
\text { cloacae } \\
\text { N=1 }\end{array}$ \\
\cline { 2 - 5 } & $\mathbf{S \%}$ & $\mathbf{S \%}$ & $\mathbf{S \%}$ & $\mathbf{S \%}$ \\
\hline Amikacin & $\mathbf{6}$ & $\mathbf{3}$ & $\mathbf{1}$ & $\mathbf{1}$ \\
\hline Aoxicillin/Clavulanic acid & $\mathbf{5}$ & $\mathbf{2}$ & $\mathbf{1}$ & $\mathbf{1}$ \\
\hline Ceftriaxon & $\mathbf{2}$ & $\mathbf{0}$ & $\mathbf{0}$ & $\mathbf{0}$ \\
\hline Piperacillin/Tazobbactam & $\mathbf{4}$ & $\mathbf{2}$ & $\mathbf{1}$ & $\mathbf{0}$ \\
\hline Levofloxacin & $\mathbf{4}$ & $\mathbf{1}$ & $\mathbf{0}$ & $\mathbf{0}$ \\
\hline Gentamicin & $\mathbf{5}$ & $\mathbf{2}$ & $\mathbf{1}$ & $\mathbf{1}$ \\
\hline Ceftazidime & $\mathbf{2}$ & $\mathbf{1}$ & $\mathbf{0}$ & $\mathbf{1}$ \\
\hline Tobramycin & $\mathbf{3}$ & $\mathbf{1}$ & $\mathbf{1}$ & $\mathbf{0}$ \\
\hline Cefotaxime & $\mathbf{2}$ & $\mathbf{1}$ & $\mathbf{0}$ & $\mathbf{0}$ \\
\hline Trimethoprime- & $\mathbf{3}$ & $\mathbf{1}$ & $\mathbf{1}$ & $\mathbf{1}$ \\
Sulphamethoxazole & $\mathbf{4}$ & $\mathbf{1}$ & $\mathbf{1}$ & $\mathbf{1}$ \\
\hline
\end{tabular}

\section{Discussion}

The prompt diagnosis and effective treatment are necessary to prevent complications and to reduce mortality from Blood Stream Infections (Latif, et al.2009). In this study, out of 90 neonatal blood specimens, the frequency of positive blood culture that indicated true bacteremia in the studied patients was 36 cases. In a study done in India, the positivity of blood culture was 42\% (770/1828) (Shafazand, and Weinacker ;2010). In this study, the coagulase-negative staphylococci were the most common isolates as in other studies (Amita, et. al.; 2003\&Kalantar, et al.; 2008).

\section{References}

Amita, J.; Indranil, R.; Mahendra, K.G.; Mala, K. and Agarwal, S.K. (2003). Prevalence of extended-spectrum S-lactamase- prou- cinggram-negative bacteria in bacteremiacaemic neonates in a tertiary care hospital. J. Med. Microbiol. 52: 421-25.

Arientová, S.; Beran, O.; Štefan, M.; Čurdová, M. and Holub, M. (2018). Bacteremia due to Staphylococcus aureus - the importance of appropriate management. Epidemiol Mikrobiol Imunol. 67(2): 88-91.

Banik, A.; Bhat, S. H.; Kumar, A.; Palit, A. and Snehaa, K. (2018). Bloodstream infections and trends of antimicrobial sensitivity patterns at Port Blair. J Lab Physicians. 10(3): 332-337.

Berit, E. C.; Maria, P. S.; Jorg, G.; Salima, M.; Martin, K. and Oleg, K. (2006). Identification and characterization of bacterial pathogens causing bloodstream infections by DNA microarray. J Clin Microbiol. 44(7): 2389-2397.

Butler-Laporte, G.; De L'Étoile-Morel, S.; Cheng, M. P,; McDonald, E. G. and Lee, T. C. (2018). MRSA colonization status as a predictor of clinical infection: A systematic review and meta-analysis. J. Infect. 77(6): 489-495.

CLSI, (Clinical and Laboratory Standards Institute) (2011). Performance standard for antimicrobial susceptibility testing; Twenty-First informational supplement. M100-S21. 31(1).

Connell, T. G.; Rele, M. and Cowley, D. (2007). How reliable is a negative blood culture result? Volume of blood submitted for culture in routine practice in a children's hospital. Pediatrics. 119: 891-894.

Gaynes, R. and Edwards, J.R. (2005). National Nosocomial Infections Surveillance, System. Overview of nosocomial infections caused by gram-negative bacilli. Clin Infect Dis. 41: 848-856.

Hussein, N. H.; Taha, B. M.; Rasool, K. H. and Hussein, J. D. (2015). Study the Prevalence and Antimicrobial Susceptibility Pattern of Bacteria Isolated from Blood Cultures of Children in Baghdad. INDIAN JOURNAL OF RESEARCH. 4(6):37-40.

Kalantar, E.; Motlagh, M.; Lordnejad, H. and Beiranvand, S. (2008). The Prevalence of Bacteria Isolated from Blood Cultures of Iranian Children and Study of their Antimicrobial Susceptibilities. Jundishapur Journal of Natural Pharmaceutical Products. 3(1): 1-7.

Latif, S.; Anwar, M. S. and Ahmad, I. (2009). BACTERIAL PATHOGENS RESPONSIBLE FOR BLOOD STREAM INFECTION (BSI) AND PATTERN OF DRUG RESISTANCE IN A TERTIARY CARE HOSPITAL OF LAHORE. Biomedica. 25: $101-105$.

Murray, P. R.; Baron, E.J. and Jorgensen, J.H. (2003). Editors: Manual of Clinical Microbiology, ed 8, Washington DC, ASM Press. 
Murty, D.S. and Gyaneshwari, M. (2007). Blood cultures in paediatric patients: A study of clinical impact. Indian J Med Microbiol. 25: 220-224.

Mylotte, J. M. and Tayara, A. (2001). Blood cultur- es: clinical aspects and controversies. Eur. J. Microbiol. Infect. Dis. 9: 157-163.

Shafazand, S. and Weinacker, A. B. (2010). Blood cultures in the critical care unit: improving utilization and yield. Chest. 122(5): 1727-1736.

Shahla, L.; Anwar M. S. and Ahmad, I..(2009).Bacterial Pathogens Responsible for Blood Stream Infection (BSI) and Pattern of Drug Resistance in a Tertiary Care Hospital of Lahpre. Biomedica. 25: $101-105$.

WHO, (World Health Organization). (2003). Basic laboratory procedures in clinical bacteriology. $2^{\text {nd }}$ ed. Geneva, Switzerland. 